\title{
Psychological Distress Increases 30-Fold Among People with HIV in the First Year on ART in Nigeria-a Call for Integrated Mental Health Services
}

\author{
Leslie J. Pierce ${ }^{1}$. Susan Regan ${ }^{2} \cdot$ Ifeoma Idigbe $^{3} \cdot$ Juliet Adeola $^{4} \cdot$ Zaidat Musa $^{3}$ - Oliver Ezechi ${ }^{3} \cdot$ Bibilola Oladeji $^{5}$. \\ Oye Gureje ${ }^{5} \cdot$ Kenneth A. Freedberg ${ }^{2,6,8,9} \cdot$ Prosper Okonkwo ${ }^{4} \cdot$ Aima A. Ahonkhai $^{1,7}$
}

Accepted: 14 February 2022 / Published online: 28 February 2022

(c) International Society of Behavioral Medicine 2022, corrected publication 2022

\begin{abstract}
Background Few studies have longitudinally assessed psychological distress among people with HIV (PWH) initiating ART in resource-limited settings.

Method Baseline, 6-month, and 12-month psychological distress were measured in a Nigerian cohort newly initiating therapy; the relationship between baseline factors and psychological distress at 12 months was assessed; and the association between psychological distress at 12 months and care retention or immunologic failure was determined.

Results Among 563 patients, median age was 38 years (IQR: $33-46$ years), 62\% were female, and 51\% were married. Psychological distress increased from $3 \%$ at baseline to $34 \%$ at 12 months. Age (aOR 1.28, 95\% CI 1.06-1.56), female sex (aOR 2.89, 95\% CI 1.93-4.33), lack of disclosure (aOR 4.32, 95\% CI 2.48-7.51), and time on ART (6 months [aOR 6.91, 95\% CI 3.14-15.18] and 12 months [aOR 32.63, 95\% CI 16.54-64.36]) were associated with psychological distress while being married (OR 0.42 , 95\% CI 0.30-0.61) was associated with reduced odds. Tweve-month psychological distress was associated with increased risk of immunologic failure (aOR 2.22, 95\% CI 1.31-3.82).

Conclusion The risk of psychological distress increased 30-fold in the first year on therapy in PWH in Nigeria.
\end{abstract}

Keywords Mental health $\cdot$ Psychological distress $\cdot$ Immunologic failure $\cdot$ ART initiation

Aima A. Ahonkhai

aimalohi.a.ahonkhai@vumc.org

1 Institute for Global Health, Vanderbilt University Medical Center, 2525 West End Ave, Suite 750, Nashville, TN 37203 , USA

2 Division of General Internal Medicine, Massachusetts General Hospital, Boston, MA, USA

3 Nigerian Institute of Medical Research, Lagos, Nigeria

4 APIN Public Health Initiatives (APIN), Abuja, Nigeria

5 Department of Psychiatry, College of Medicine, University of Ibadan, Ibadan, Nigeria

6 Medical Practice Evaluation Center, Massachusetts General Hospital, Boston, MA, USA

7 Division of Infectious Diseases, Vanderbilt University Medical Center, Nashville, TN, USA

8 Harvard Medical School, Boston, MA, USA

9 Department of Health Policy and Management, Harvard T H Chan School of Public Health, Boston, MA, USA

\section{Introduction}

Nigeria is the most populous nation in Africa, and home to over 190 million inhabitants [1]. With an estimated 1.9 million people with HIV (PWH) across the country, Nigeria has the $4^{\text {th }}$ largest HIV epidemic worldwide [2]. Despite current access to antiretroviral therapy (ART) having tripled in Nigeria since 2010, only 52\% of PWH are on antiretroviral therapy (ART) and $42 \%$ of PWH are virally suppressed [3, 4]. These outcomes fall far short of UNAIDS 95-95-95 targets which call for 95\% of PWH to be aware of their diagnosis, $95 \%$ of those diagnosed to be on ART, and $95 \%$ of those on ART to be virally suppressed by 2030 [5-7].

A growing literature suggests that unmet mental health needs may contribute to the gap between care continuum targets and country performance in Nigeria, as well as in other resource-limited settings [8]. These data focus primarily on depression or related measures such as psychological distress. The latter, psychological distress, defines a state of emotional suffering that impairs daily functioning and may encompass 
common mental disorders such as depression, anxiety, and post-traumatic stress [8-10]. Psychological distress is prevalent among approximately $10-35 \%$ of PWH in sub-Saharan Africa (SSA) [8-12]. Depression is much more common among PWH (13-78\%) than among the general population (5\%) $[13,14]$.

Receiving an HIV diagnosis is often accompanied by a number of psychological challenges that may affect one's coping capacity including managing disclosure to family, friends, and/or sexual partners, and contending with perceived stigma and loss of social support [15]. These important psychosocial factors can fuel a vicious cycle of depression and diminishing self-efficacy, which can threaten treatment adherence and engagement in HIV care [14, 16, 17].

The first year following enrollment in HIV care may be a particularly vulnerable period, as patients attempt to adjust to the psychosocial stressors related to the diagnosis, as well as the need to establish routines that require frequent attendance at healthcare appointments and adherence to a daily medication regimen needed to achieve and maintain viral suppression [14, 16, 17]. It may therefore not be surprising that this period is often associated with very high rates of attrition from care and increased HIV-associated morbidity and mortality [18-20]. However, the contribution of psychological distress to high attrition rates and increased risk for morbidity and mortality in the first year following diagnosis and enrollment in care is not well characterized [18-20]. Much of the available data on the prevalence and implications of psychological distress and depression are based on cross-sectional studies that do not always include this highrisk period after diagnosis [8, 9, 21-23].

The objectives of this analysis were to measure the prevalence of psychological distress in the first year after ART initiation, identify socioeconomic drivers of psychological distress, and assess the relationship between psychological distress, engagement in care, and immunologic response to ART among patients establishing HIV care in Lagos, Nigeria. Grounded in the tenets of Anderson's Model of Health Behavior - which describes how environmental, individual predisposing, and enabling factors impact health behaviors including healthcare utilization and health outcomes-we hypothesized that higher psychological distress would be associated with poor engagement in HIV care and disease control (measured by change in CD4 cell count while on ART).

\section{Methods}

\section{Setting}

The study was set at the Nigerian Institute for Medical Research (NIMR) in Lagos, Nigeria. NIMR's HIV clinic is a President's
Emergency Plan for AIDS Relief (PEPFAR)-supported clinic that began providing care in 2002. NIMR offers comprehensive HIV care services including HIV counseling and testing, ART provision, and on-site laboratory services (hematology, chemistries, CD4 cell count, and viral load). NIMR currently has 7,351 patients enrolled in HIV care.

\section{Study Design}

A prospective cohort study was conducted of patients who enrolled in the NIMR HIV clinic between November 2013 and May 2014, were deemed ART-eligible, and completed the required counseling for ART initiation. Individuals were eligible for enrollment into the study if they (1) were at least 18 years of age, (2) initiated ART 90 days prior to or post study enrollment, (3) were not pregnant, and (4) were fluent in English (the official language in Nigeria), Igbo, Yoruba, or Hausa (the primary languages spoken in Nigeria). At the time of the study, patients were considered eligible for ART if any of the following criteria were met: CD4 count below 350 cells $/ \mathrm{mm}^{3}$, WHO stage 3 or 4 disease, active tuberculosis, or required treatment for hepatitis B virus infection [25]. Eligible patients who consented to study participation were followed for 1 year, and completed comprehensive questionnaires at baseline (study entry), 6 months, and 12 months. Questionnaires were entered into a REDCap database. Psychological distress was assessed in addition to a range of socio-demographic factors. According to national guidelines, after ART initiation, patients were scheduled to be seen for adherence counseling, clinical examination, and tuberculosis (TB) symptom screening at 2, 4, 8, and 12 weeks. Subsequently, patients were seen for ART pickup every 4 weeks, clinical examination and adherence counseling every 12 weeks, and laboratory testing (including CD4 count and HIV viral load) every 24 weeks [25]. Clinical visit dates and CD4 count laboratory results were abstracted from the electronic medical record.

\section{Data Elements}

Psychological Distress The primary outcome of interest for this analysis was psychological distress. Psychological distress was assessed using the World Health Organization 20-item Self-Reporting Questionnaire (SRQ-20), a tool that has been validated for use in outpatient facilities located in low- and middle-income countries [24]. The SRQ-20 is designed to screen for psychiatric disturbance and incorporates questions about symptoms and problems likely to be present in individuals with common mental disorders such as depression and anxiety. Scores range from 0 to 20 , with higher scores correlating with higher levels of distress and probable affective disorders [24]. Based on the application of this scale in similar geographic and clinical populations, 
we defined psychological distress as clinically significant at a score $\geq 5$ [25-27]. Suicidal ideation is assessed in the SRQ-20 through the question, "has the thought of ending your life been on your mind?" [24]. Psychological distress and suicidality were measured at baseline and at 12 months.

Demographic Characteristics Individual-level demographics were collected from baseline questionnaires at study entry and included the following: (1) sex, (2) age at time of the study, (3) self-reported monthly income, (4) education (primary, secondary, tertiary, unknown), (5) marital status (single, married, separated, divorced, widowed, unknown). Additionally, self-reported HIV disclosure was assessed at baseline, 6 months, and 12 months.

Disclosure was defined as "before ART initiation" if patients had disclosed their HIV status at enrollment, "after ART initiation" if they reported not disclosing at baseline but had disclosed at the 6- or 12-month follow-up visit, or "never" if they did not report disclosure at all during the 12-month follow-up period.

Clinical Measures CD4 count was measured at baseline (within 90 days of study enrollment), and at 4-monthly intervals in the first year on ART per clinic protocol as described above. CD4 data were used to define immunologic failure by either (1) decline in CD4 count below the baseline value (if baseline value was $<350$ cells $/ \mu \mathrm{L}^{3}$, this caveat was added given the threshold for ART initiation during the period of this analysis) or (2) CD4 count persistently less than 100 cells $/ \mu \mathrm{L}^{3}$ during the follow-up period. Clinic, laboratory, and pharmacy visit data were used to define retention. Retention in care was assessed in two ways: (1) care interruption, defined as having a period 90 days or more without a clinic, pharmacy, or laboratory visit, but with return to care within the 12-month follow-up period; (2) loss to follow-up (LTFU), defined as having a period of 90 days or more without a clinic, pharmacy, or laboratory visit, but without return to care within the 12-month follow-up period [28-32]. Given inconsistent availability of viral load data, this variable was not included.

\section{Statistical Analysis}

Baseline Demographic and Clinical Parameters Baseline demographic and clinical parameters, including median age, sex, level of education, income (categorized as between $\$ 1$ and \$5 USD/day, and > \$5USD/day), marital status, and median CD4 count, were presented as frequencies and means across the entire cohort.

Disclosure and Distress over Time Disclosure status and psychological distress were summarized across the cohort at baseline (prior to ART initiation), 6 months, or 12 months after ART initiation according to the categorical definitions above. Change in individual distress symptoms (assessed via specific questions on the SRQ-20) at 6 and 12 months was assessed using McNemar's tests for matched samples.

Prevalence and Predictors of Psychological Distress We assessed demographic and clinical predictors of psychological distress at baseline and 6- and 12-month follow-up using logistic regression models for panel data (generalized estimating equations with robust standard errors). In these analyses, disclosure status (disclosed, did not disclose, or unknown disclosure) and CD4 count $(<200, \geq 200$, or not available) were time-varying and assessed at each time point (baseline, 6 months, and 12 months). We present unadjusted odds ratios (OR) and odds ratios adjusted for all predictors (aOR) with $95 \%$ confidence intervals $(\mathrm{CI})$.

Association Between Psychological Distress Clinical Outcomes Multivariate logistic regression models were used to assess the association between psychological distress and immunologic failure at 12 months, adjusting for sex, marital status, age, education, disclosure status, and baseline CD4 count. Adjusted odds ratios (aOR) and 95\% confidence intervals (CIs) were presented. The impact of distress on care continuity was assessed in a multinomial logistic regression with a 3-level outcome: continuous care vs. unplanned interruptions vs. lost to follow-up. Adjusted relative risk ratios (aRRR) and 95\% CIs, adjusted for the same covariates, were reported. In the latter analysis, multiple imputation using chained equations was used to impute $\mathrm{CD} 4$ counts for 18 patients with missing values.

Sensitivity Analysis To further explore the relationship between immunologic failure and psychologic distress, we created variables for immunologic failure at baseline and 6 months (in addition to 12 months), and summarized prevalence of psychological distress by immunologic failure and disclosure status at each of these time points. Multivariable logistic regression for panel data was again used (generalized estimating equations with robust standard errors) to assess the relationship between current immunologic failure and current psychological distress.

Statistical analysis was conducted with Stata Statistical Software (StataCorp. 2017. Stata Statistical Software: Release 15. College Station, TX, USA).

\section{Results}

\section{Cohort Description}

A total of 761 patients were screened. Seventy-four percent were eligible and could be linked to clinic data. Among this eligible population, the response rate for the 12-month survey was $86 \%$, leaving 485 patients in the analysis cohort. 
Table 1 Study population descriptive characteristics

\begin{tabular}{ll}
\hline Age (median, IQR) & $38[33-46]$ \\
Female sex (no., \%) & $303(62)$ \\
Marital status (no., \%) & \\
$\quad$ Married & $249(51)$ \\
$\quad$ Unmarried & $236(49)$ \\
Monthly income (no., \%) & \\
180-29,999 (1-5 USD/day) & $204(42)$ \\
$\geq 30000$ ( $\geq 5$ USD/day) & $257(53)$ \\
Unknown & $24(5)$ \\
Education (no., \%) & \\
None/primary & $77(16)$ \\
Secondary/tertiary & $407(84)$ \\
Disclosure (no., \%) & \\
Before ART initiation & $402(83)$ \\
After ART initiation & $37(8)$ \\
Never & $27(6)$ \\
No follow-up* & $19(4)$ \\
CD4 count (cells/ $\mu \mathbf{L}^{3}$ ) & \\
$<200$ & $189(39)$ \\
$\geq 200$ & $278(57)$ \\
Unknown & $18(4)$ \\
Elinically significant psychologic distress $(\%, 95 \%$ CI) & $2.7(1.6-4.6)$ \\
Month 6 & $12.0(9.4-15.3)$ \\
Month 12 & $33.8(29.7-38.2)$ \\
\hline &
\end{tabular}

$I Q R$ interquartile range, $C I$ confidence interval

The median age was 38 years (IQR 33-46), 62\% $(n=303)$ were female, $51 \%(n=249)$ were married, and $84 \%(n=407)$ had secondary or higher education. Among those who were married, $35 \%(n=86)$ reported that their spouse was also living with HIV. Forty-two percent of the cohort made the equivalent of $1-5$ USD per day, and $53 \%(n=257)$ made $>5$ USD/day. Baseline CD 4 count was $<200$ cells $/ \mathrm{mL}^{3}$ for $39 \%$ of patients $(n=189)$, and $\geq 200$ cells $/ \mathrm{mL}^{3}$ for $57 \%(n=278)$ (Table 1). Patients who were excluded from the analysis due to missing 12-month follow-up data $(n=78)$ were less likely to report significant distress at 6 months (3\% vs. $12 \%$, $p=0.04$ ) and were more likey to having missing monthly income data ( $13 \%$ vs. $5 \%, p=0.025)$.

\section{Disclosure and Distress in the First Year on ART}

Psychological distress was present in 3\% of the cohort at baseline, $12 \%$ at 6 -month follow-up, and $34 \%(n=164)$ at 12-month follow-up (Fig. 1). Of the 20 items on the SRQ, there was an increased rate of positive screening on 9 items between baseline and 12-month follow-up. Among these, four symptoms in particular became more present in the population over time. At the 12-month follow-up, $93 \%$ of participants indicated feeling nervous, tense, or worried (vs. $66 \%$ baseline and $72 \% 6$ months; $p<0.001$ ), $56 \%$ of respondents reported feeling unhappy (vs. $41 \%$ at baseline and $38 \%$ at 6 months; $p<0.001$ ), $73 \%$ of participants reported finding it difficult to enjoy daily activities (vs. $8 \%$ baseline and $28 \% 6$ months; $p<0.001$ ), and $69 \%$ of participants found it difficult to make decisions (vs. $8 \%$ at baseline and $36 \%$ at 6 months; $p<0.001$ ). No patients endorsed suicidality at baseline or 6 months, and only 1 patient in the cohort endorsed suicidality at the 12-month follow-up.

Most patients $(83 \%, n=402)$ reported having disclosed their HIV status at study entry and an additional $8 \%$ $(n=37)$ disclosed late (by 6 or 12 months after enrollment). The remainder reported not disclosing $(6 \%, n=27)$ or did not respond to the disclosure item at follow-up $(4 \%, n=19)$ (Table 1). Among those who disclosed, participants most commonly reported disclosure to a significant other such as a spouse, boyfriend, or girlfriend (54\%) and/or sibling (32\%). Among those who disclosed early, $31 \%$ had psychological distress 12 months after enrollment compared to $57 \%$ among those who disclosed late and 59\% among those who never disclosed at all.

\section{Factors Associated with Psychological Distress at 12-Month Follow-up}

In univariate analysis, the odds of having clinically significant psychological distress were higher at follow-up compared to baseline: OR: 4.97, 95\% CI: 2.72-9.07 at 6 months; OR: $18.55,95 \%$ CI: $10.34-33.29$ at 12 months. In addition, female sex (OR: 2.76, 95\% CI: 1.97-3.88) and lack of disclosure (OR: $1.89,95 \%$ CI: 1.24-2.88) were associated with increased odds of psychological distress, while being married was associated with reduced odds of clinically significant psychological distress (OR: 0.47, 95\% CI: 0.35-0.63) (Table 2).

In multivariate analysis, the association of time since enrollment with greater psychological distress was undiminished (aOR: 6.91, 95\% CI: 3.14-15.18 and aOR: 32.63, 95\% CI: 16.54-64.36 at 6- and 12-month follow-up, respectively). Each decade increase in age was associated with $28 \%$ increased odds of clinically significant distress (aOR: 1.28, 95\% CI: 1.06-1.56). Females had nearly threefold greater odds of clinically significant distress than males (aOR: 2.89, 95\% CI: 1.93-4.33). Not having disclosed one's HIV status was associated with increased odds of clinically significant distress (aOR: 4.32, 95\% CI: 2.48-7.51) compared to previous disclosure. Being married remained a significant protective factor in adjusted analysis (aOR $0.42,95 \%$ CI 0.30-0.61) (Table 2). 
Fig. 1 Psychological distress over time in a cohort newly engaged in HIV care. Psychological distress, defined by a score $\geq 5$ on the World Health Organization's 20-item self-reporting questionnaire, was present in $3 \%$ of the cohort at baseline, $12 \%$ at 6-month follow-up, and $34 \%$ at 12 -month follow-up

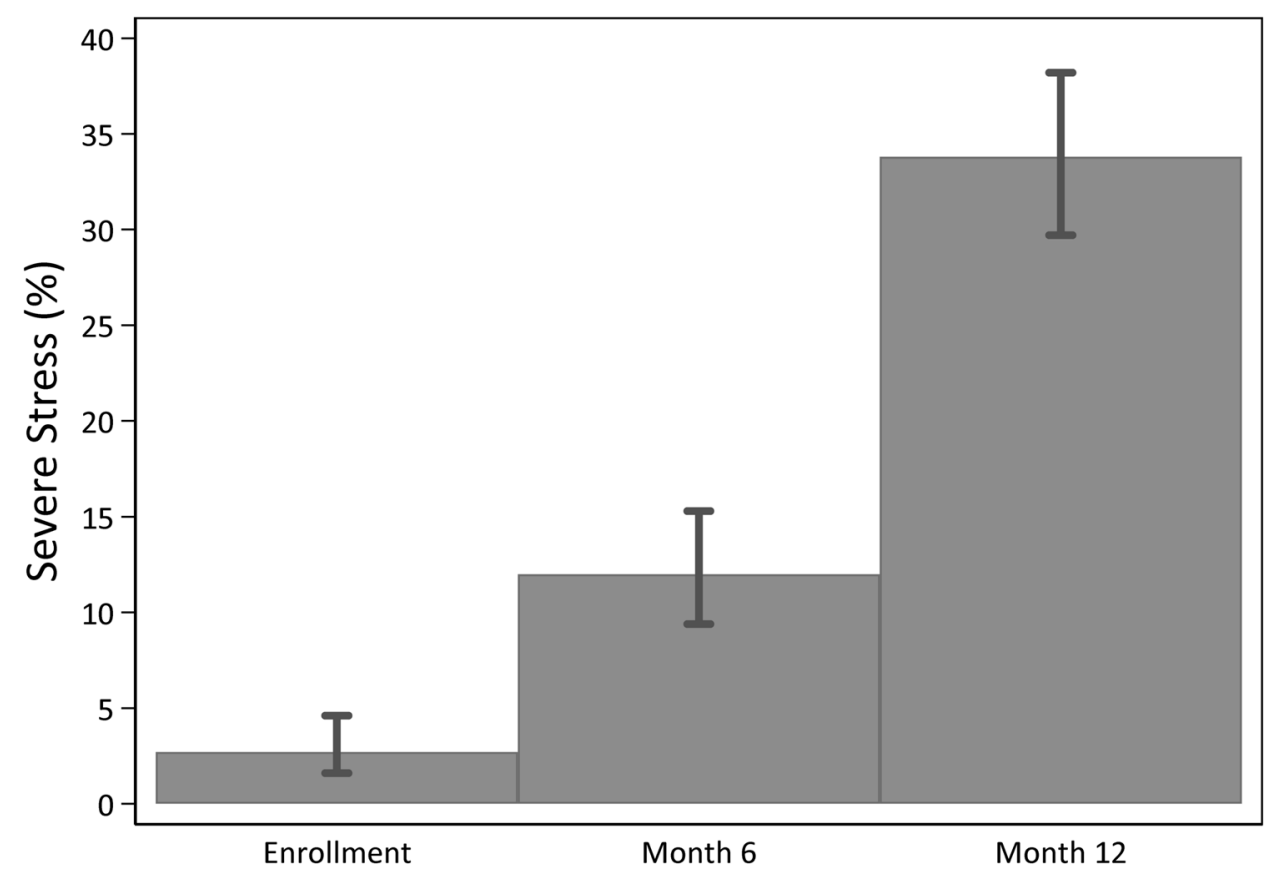

Table 2 Logistic regression model assessing predictors of psychological distress 12 months after ART initiation

\begin{tabular}{|c|c|c|c|c|}
\hline & OR & 95\% CI & aOR & $95 \% \mathrm{CI}$ \\
\hline Age (per decade change) & 1.10 & $0.98-1.28$ & 1.28 & $1.06-1.56$ \\
\hline \multicolumn{5}{|l|}{ Sex } \\
\hline Male & 1 & & 1 & \\
\hline Female & 2.76 & $1.97-3.88$ & 2.89 & $1.93-4.33$ \\
\hline \multicolumn{5}{|l|}{ Marital status } \\
\hline Unmarried & 1 & & 1 & \\
\hline Married & 0.47 & $0.35-0.64$ & 0.42 & $0.30-0.61$ \\
\hline \multicolumn{5}{|l|}{ Monthly income (NGN) } \\
\hline 180-29999 & 1 & & 1 & \\
\hline $\begin{array}{l}\geq 30,000(\geq 5 \text { USD/ } \\
\text { day) }\end{array}$ & 0.88 & $0.65-1.19$ & 1.08 & $0.76-1.55$ \\
\hline Unknown & 1.41 & $0.92-2.16$ & 1.66 & $0.92-3.00$ \\
\hline \multicolumn{5}{|l|}{ Education } \\
\hline None/primary & 1 & & 1 & \\
\hline Secondary/tertiary & 0.71 & $0.49-1.01$ & 0.83 & $0.51-1.33$ \\
\hline \multicolumn{5}{|l|}{ Disclosure } \\
\hline Yes & 1 & & 1 & \\
\hline No & 1.89 & $1.24-2.88$ & 4.32 & $2.48-7.51$ \\
\hline Unknown & 0.18 & $0.02-1.34$ & 0.09 & $0.01-0.84$ \\
\hline \multicolumn{5}{|l|}{ CD4 count $\left(\right.$ cells $\left./ \mu L^{3}\right)$} \\
\hline$<200$ & 1 & & 1 & \\
\hline$\geq 200$ & 3.10 & $1.84-5.23$ & 1.23 & $0.65-2.32$ \\
\hline Unknown & 2.63 & $1.57-4.40$ & 1.33 & $0.67-2.62$ \\
\hline \multicolumn{5}{|l|}{ Follow-up } \\
\hline Baseline & 1 & & 1 & \\
\hline 6 months & 4.97 & $2.72-9.07$ & 6.91 & $3.14-15.18$ \\
\hline 12 months & 18.55 & $10.34-33.29$ & 32.63 & $16.54-64.36$ \\
\hline
\end{tabular}

$A R T$ antiretroviral therapy, $N G N$ Nigerian Naira, USD US dollar
Disclosure, Age, Sex, and Psychological Distress

The highest prevalence of psychological distress at 12 months was observed among females $\geq 35$ years who disclosed their HIV status late or not at all. These women had a prevalence of clinically significant of psychological distress of $70 \%$ if unmarried, and $67 \%$ if married. In contrast, $27-29 \%$ of males $\geq 35$ years who disclosed their HIV status early had psychological distress at 12 months (Fig. 2).

\section{Retention in Care and Immunologic Failure}

Eleven percent $(n=54)$ of patients had unplanned interruptions in care and $10 \%(n=48)$ were lost to follow-up at 12 months. However, 12-month psychological distress was not significantly associated with care interruption or loss to follow-up over the 12-month study period (aRRR $1.22,95 \%$ CI $0.64-2.32$ and aRRR $0.91,95 \%$ CI 0.46-1.82, respectively) (Table 3 ). Among the $64 \%$ of patients with available CD4 data, $15 \%(n=53)$ met WHO criteria for immunologic failure after 6-12 months on ART. Psychological distress at the end of the 12-month study period was significantly associated with risk of immunologic failure in both univariate (OR 2.42, 95\% CI 1.52-3.85) and adjusted (aOR 2.22, 95\% CI 1.31-3.76) analyses (Table 4). Additionally, in adjusted analysis, current immunologic failure was associated with increased odds of current distress (aOR $2.44,95 \%$ CI 1.63-3.68). Seventeen percent of indivuals with immunologic failure at 6 months and $48 \%$ of individuals with immunologic failure at 12 months had clinically significant distress (compared to $6 \%$ and $28 \%$ respectively 


\begin{tabular}{|c|c|c|c|c|c|}
\hline \multirow{2}{*}{ Disclosure* } & \multirow{2}{*}{ Age } & \multicolumn{2}{|c|}{ Female $(n=303)$} & \multicolumn{2}{|c|}{ Male $(n=181)$} \\
\hline & & Unmarried & Married & Unmarried & Married \\
\hline \multirow{2}{*}{$\begin{array}{c}\text { Before } \\
\text { ART- } \\
(n=402)\end{array}$} & $<35$ & $44 \%$ & $22 \%$ & $24 \%$ & $0 \%$ \\
\hline & $>=35$ & $48 \%$ & $30 \%$ & $33 \%$ & $18 \%$ \\
\hline \multirow{2}{*}{$\begin{array}{c}\text { After } \\
\text { ART/Never } \\
(n=64)\end{array}$} & $<35$ & $55 \%$ & & $17 \%$ & $0 \%$ \\
\hline & $>=35$ & $70 \%$ & $67 \%$ & $25 \%$ & $29 \%$ \\
\hline
\end{tabular}

Fig. 2 Psychological distress by demographic group. This heat map highlights differences in the prevalence of clinically significant psychological distress among patient subgroups. The numbers in the cells reflect the percent of patients within each demographic and dis-

in individuals without immunologic failure). At both time points, the prevalence of distress was higher among individuals with immunolgic distress who had not disclosed their HIV status compared to those who had (60\% vs. $13 \%$ at 6 months, $83 \%$ vs. $47 \%$ at 12 months) (see Supplementary Tables).

\section{Discussion}

A prospective cohort of people newly enrolled in HIV care in a large treatment program in Lagos, Nigeria, was followed to assess psychological distress and found striking results. While only $3 \%$ of patients had showed an indication of psychological distress at treatment initiation, 34\% reported clinically significant psychological distress at study end, representing greater than a 30-fold increased adjusted risk of distress after 12 months in care. Psychological distress at 12 months was associated with a greater than twofold risk of immunologic failure and was most prevalent among older women who had not disclosed their diagnosis by the time they established care in the HIV clinic. While our data do not allow us to draw conclusions about the causal nature of immunologic failure and psychological distress, this finding is nevertheless salient in a region of the world with limited infrastructure for the provision of mental health service [33]. In Nigeria, in particular, it is estimated that fewer than $10 \%$ of individuals in need receive evidence-based mental health interventions [33, 34].

These findings add to the body of literature describing a high prevalence of psychological distress among $\mathrm{PWH}$, and its association with poor HIV outcomes [18-20]. Many of these studies were cross-sectional in nature and reported a prevalence of psychological distress or depression ranging between 10 and 35\% [8-12]. The longitudinal follow-up of the patients in the year following enrollment in HIV care closure group who reported clinically significant psychological distress at 12 months. The cells are color-coded. Green cells indicate relatively low and red cells indicate relatively high prevalence of distress

suggests an important temporal component to the development of psychological distress, likely driven by the complicated psychosocial dynamics of living with an HIV diagnosis [35]. For some PLWH, the very act of taking ART itself serves as a constant reminder of HIV, shame, and internalized stigma. In this way, though life-saving, longer time on HIV may also drive significant distress in some [36, 37]. It is important to note that this analysis was restricted to individuals who were eligible for and were prescribed ART at clinic enrollment. We did not have data on ART adherence (only on whether it was prescribed), so it is unclear if "time on ART" represented time on treatment, or simply duration of ART eligibility. As such, these findings cannot easily be attributable to sequelae from untreated HIV.

Despite increased prevalence of distress in the first year on ART, it was notable that only 1 patient in this cohort reported suicidal ideation (at 12 months, but not at baseline or 6 months). Accordingly, the prevalence of suicidality is much lower than in other reports from Nigeria and from subSaharan Africa. One study from Lagos, Nigeria, reported a prevalence of SI of $7.25 \%$ in the general popilation; others among PLWH in Nigeria have reported a wide range of suicidal ideation from as low as $3 \%$ to as high as $15 \%$ $[12,38,39]$. While the reasons for these differences are not entirely clear, several factors may contribute to these differences including differences in screening tools (none of these reports utilized the SRQ-20 to screen for mental disorders or suicidality), age differences in the chorots (suicidality was highest among the oldest patients), and other possible cultural differences impacting inhibitions around discussing mental health [40]. The potential intersecting stigma of reporting about suicidal thoughts while also contending with a new stigmatizing illness could also have influenced ascertainment in our cohort of PLWH.

Several studies have described associations between psychological distress and depression on poor medication 
Table 3 Association between psychological distress and care interruption or loss to follow-up 12 months after ART initiation in a Nigerian cohort

\begin{tabular}{|c|c|c|}
\hline & aRRR* & 95\% CI \\
\hline \multicolumn{3}{|l|}{$\geq 1$ interruptions in care } \\
\hline \multicolumn{3}{|l|}{ 12-month psychological distress } \\
\hline No clinically significant distress & 1.00 & \\
\hline Clinically significant distress & 1.22 & $0.64-2.32$ \\
\hline Age (per decade change) & 0.82 & $0.58-1.16$ \\
\hline \multicolumn{3}{|l|}{ Sex } \\
\hline Male & 1 & \\
\hline Female & 0.59 & $0.32-1.12$ \\
\hline \multicolumn{3}{|l|}{ Marital status (no., \%) } \\
\hline Unmarried & 1.00 & \\
\hline Married & 1.13 & $0.60-2.15$ \\
\hline \multicolumn{3}{|l|}{ Monthly income (no., \%) } \\
\hline $180-29999$ & 1.00 & \\
\hline$\geq 30000$ ( $\geq 5$ USD/day) & 0.68 & $0.37-1.26$ \\
\hline Unknown & 0.32 & $0.04-2.53$ \\
\hline \multicolumn{3}{|l|}{ Education (no., \%) } \\
\hline None/primary & 1.00 & \\
\hline Secondary/tertiary & 0.65 & $0.31-1.39$ \\
\hline \multicolumn{3}{|l|}{ Disclosure (no., \%) } \\
\hline Before ART initiation & 1.00 & \\
\hline After ART initiation/never & 1.21 & $0.57-2.59$ \\
\hline \multicolumn{3}{|l|}{ CD4 count $\left(\text { cells } / \mu \mathbf{L}^{3}\right)^{*}$} \\
\hline$<200$ & 1.00 & \\
\hline$\geq 200$ & 1.04 & $0.57-1.90$ \\
\hline \multicolumn{3}{|l|}{ Lost to follow-up } \\
\hline \multicolumn{3}{|l|}{ 12-month psychological distress } \\
\hline No clinically significant distress & 1.00 & \\
\hline Clinically significant distress & 0.91 & $0.46-1.82$ \\
\hline Age (per decade change) & 1.11 & $0.79-1.57$ \\
\hline \multicolumn{3}{|l|}{ Sex } \\
\hline Male & 1.00 & \\
\hline Female & 0.54 & $0.27-1.09$ \\
\hline \multicolumn{3}{|l|}{ Marital status (no., \%) } \\
\hline Unmarried & 1 & \\
\hline Married & 0.64 & $0.32-1.26$ \\
\hline \multicolumn{3}{|l|}{ Monthly income (no., \%) } \\
\hline 180-29999 & 1.00 & \\
\hline$\geq 30,000$ ( $\geq 5$ USD/day) & 0.67 & $0.34-1.32$ \\
\hline Unknown & 3.00 & $0.94-9.62$ \\
\hline \multicolumn{3}{|l|}{ Education (no., \%) } \\
\hline None/primary & 1.00 & \\
\hline Secondary/tertiary & 0.91 & $0.40-2.06$ \\
\hline \multicolumn{3}{|l|}{ Disclosure (no., \%) } \\
\hline Before ART initiation & 1.00 & \\
\hline After ART initiation/never & 1.08 & $0.46-2.52$ \\
\hline \multicolumn{3}{|l|}{ Stigma } \\
\hline \multicolumn{3}{|l|}{ CD4 count $\left(\text { cells } / \mu L^{3}\right)^{*}$} \\
\hline$<200$ & 1.00 & \\
\hline
\end{tabular}

Table 3 (continued)

\begin{tabular}{lll}
\hline & aRRR* & 95\% CI \\
\hline$\geq 200$ & 0.40 & $0.21-0.75$ \\
\hline
\end{tabular}

*ARRR adjusted relative risk ratio

adherence, and higher rates of virologic failure [18-20]. Conversely, others have described how adherence to ART may actually improve symptoms of depression and psychological distress by impacting metabolism of immunologically active amino acids [41, 42]. Poor medication adherence is a possible path to the increased risk of immunologic failure observed in the cohort $[18,43,44]$. Notably, we found that individuals with immunologic failure had a higher prevalence of psychological distress than those with better disease control supporting that disease progression itself may be a source of distress. This relationship was exacerbated in PWH who had not disclosed their HIV status. Other potential contributors to poor immunologic function have

Table 4 Association between psychological distress and immunologic failure 12 months after ART initiation in a Nigerian cohort

\begin{tabular}{|c|c|c|c|c|}
\hline & OR & 95\% CI & aOR & 95\% CI \\
\hline \multicolumn{5}{|l|}{ 12-month psychological distress } \\
\hline $\begin{array}{l}\text { No clinically significant } \\
\text { distress }\end{array}$ & 1.00 & & & \\
\hline Clinically significant distress & 2.42 & $1.52-3.85$ & 2.22 & $1.33-3.76$ \\
\hline Age (per decade change) & 0.93 & $0.73-1.19$ & 0.86 & $0.64-1.14$ \\
\hline \multicolumn{5}{|l|}{ Sex } \\
\hline Male & 1.00 & & 1.00 & \\
\hline Female & 1.91 & $1.17-3.10$ & 1.67 & $0.97-2.88$ \\
\hline \multicolumn{5}{|l|}{ Marital status (no., \%) } \\
\hline Unmarried & 1.00 & & 1.00 & \\
\hline Married & 0.97 & $0.62-1.52$ & 1.46 & $0.85-2.49$ \\
\hline \multicolumn{5}{|l|}{ Monthly income (no., \%) } \\
\hline 180-29999 & 1.00 & & 1.00 & \\
\hline$\geq 30000$ ( $\geq 5$ USD/day $)$ & 0.96 & $0.60-1.52$ & 0.94 & $0.57-1.55$ \\
\hline Unknown & 0.44 & $0.12-1.58$ & 0.28 & $0.07-1.05$ \\
\hline \multicolumn{5}{|l|}{ Education (no., \%) } \\
\hline None/primary & 1.00 & & 1.00 & \\
\hline Secondary/tertiary & 0.88 & $0.48-1.62$ & 0.79 & $0.40-1.55$ \\
\hline \multicolumn{5}{|l|}{ Disclosure (no., \%) } \\
\hline Before ART initiation & 1.00 & & 1.00 & \\
\hline After ART initiation & 1.71 & $0.79-3.70$ & 1.45 & $0.63-3.44$ \\
\hline Never & 1.71 & $0.59-4.95$ & 1.08 & $0.34-3.42$ \\
\hline No follow-up & 0.37 & $0.08-1.65$ & 0.39 & $0.08-1.89$ \\
\hline \multicolumn{5}{|l|}{ CD4 count $\left(\right.$ cells $\left./ \mu L^{3}\right)$} \\
\hline$<200$ & 1.00 & & 1.00 & \\
\hline$\geq 200$ & 2.71 & $1.61-4.57$ & 2.40 & $1.40-4.14$ \\
\hline
\end{tabular}

$A R T$ antiretroviral therapy 
been described in this population. Indeed, people living with HIV, who have either depression or psychological distress, have been found to exhibit disease progression despite optimal adherence to ART [45]. Potential mechanisms that have been proposed for poor immunologic function are increased cytotoxic CD8 T-cell activation, lower natural killer cell activity, and direct activity of stress hormones like cortisol and norepinephrine in the face of depression [46-49]. Regardless of the mechanism of poor immunologic function, untreated clinically significant distress in this setting may reflect an important threat to achieving both individual health and UNAIDS 95-95-95 goals. The overlapping burden of COVID-19 and social isolation on a global scale may further exacerbate this threat [50].

While a very strong association between psychological distress and immunologic failure was observed in the cohort, an association was not found between psychological distress and other important clinical outcomes, including interruptions in care and loss to follow-up as measures of retention in HIV care. However, other studies, including one from Rwanda, have reported up to a fourfold increased risk in the time to attrition from HIV care among individuals with untreated depression [51]. Interestingly, in Rwanda, the relationship between depression and attrition was not mediated by poor medication adherence, and may suggest a different causal relationship between depression or psychological distress and retention in care compared to depression and medication adherence [51]. While interaction in the clinic may itself be a source of distress and a reminder of one's stigmatizing illness, with a patient-centered focus, the clinic may also be an important source of social support [52]. Additional consideration in this analysis may have been insufficient follow-up time to observe the impact of distress on engagement in care, as the highest prevalence of clinically significant distress was found at 12 months - the end of the follow-up period.

Disclosure has been described as an unremitting social and psychological process of sharing critical health and personal information with others [53]. For PWH, this process may lead to either highly desired outcomes (social support, financial support, decreased disease transmission) or highly distressing outcomes (loss of employment, social isolation, stigma, physical abuse, discrimination) [53]. Consequently, the decision about if, when, and to whom one discloses is often a very challenging one. Most patients in the cohort (81\%) had disclosed their HIV status by the time they enrolled in the study (within 90 days of establishing HIV care), but delays in disclosure over the year of follow-up were associated with a fourfold increased risk of psychological distress. The magnitude of risk did not appear to differ among those who disclosed by 6 months or those who did not disclose at all during the follow-up period, compared to those who disclosed at baseline. Of individuals who did disclose their diagnosis at baseline, less than half reported to whom they disclosed. Among this subset of patients with available data, a spouse was the individual most commonly disclosed to person, followed by a sibling.

Findings about the frequency of disclosure are consistent with a meta-analysis on disclosure among PWH in Nigeria in which the prevalence of disclosure was 78\% [53]. In the same study, the vast majority of people who disclosed their HIV status, about $78 \%$, had a supportive response to their disclosure [53]. Such dynamics are not consistent across geographic and cultural contexts. For example, one qualitative study from South Africa reported that no participants experienced a supportive reaction from their sexual partners upon disclosure $[53,54]$. Nonetheless, these findings from Nigeria underscore the importance of encouraging and supporting the disclosure process, perhaps early in the treatment course, as a potential mechanism for preventing psychological distress.

Though the relationship between disclosure and social support may be complex, social support, or more importantly the lack thereof, is often negatively associated with a range of psychosocial outcomes including distress and stigma, as well as clinical outcomes such as medication adherence $[8,55]$. One study from Ethiopia found that the relationship between social support and psychological distress was confounded by high levels of enacted stigma [8]. Another study in the USA found that depressive symptoms mediated the association between social support and HIV disclosure for women. However, among men, social support was associated with depressive symptoms, but not disclosure practices $[55,56]$. While social support was not measured directly in the cohort, marital status may serve as a proxy for social support in this setting, as approximately half of the cohort was married, and a spouse was the person most often disclosed to. Additionally, about one-third of married individuals reported that his or her spouse was living with HIV. Positive support from a spouse might explain the strong protective effect of marital status in the cohort.

These data illuminate the complexity of the relationship between social support, distress, and disclosure, but also highlight important gender differences in these characteristics. In the general population, females have a greater risk of depression and affective disorders than males [57]. The same was observed in the cohort, where females had a nearly threefold increased risk of psychological distress than males, but limited data from other cohorts among PWH are mixed [58]. However, it is clear that there are important differences in coping mechanisms, and implications or effectiveness of those coping mechanisms may explain some of the reasons that males and females report or face varying levels of depression and distress [56, 59]. One study from India found that seeking social support from others protected men from depression at all income levels, but only protected 
high-income women [60]. Other studies suggest that females are more reliant on social support and have greater support systems than males [59].

This study has important strengths and weaknesses. In this observational cohort, the association between psychological distress and virologic control was unable to be assessed due to missing data on this clinical outcome. Immunologic failure was used as a surrogate, though the authors recognize this is an imperfect measure of disease control. The contribution of other important psychosocial factors, such as stigma, was unable to be incorporated and did not allow for a full assessment of the future impact of increasing distress rates on clinical outcomes, or changes in distress over a longer time horizon. Our data were collected prior to Nigeria's rollout of the testand-treat policy in 2016. The patients in our analysis were all eligible for ART under an earlier treatment paradigm and may have represented an overall sicker group. Patients with missing 12-month follow-up data comprised about $16 \%$ of the cohort, but were less likely to report clinically significant distress at 6 months which could impact our prevalence estimates for 12-month outcomes. Additionally, without data on treatment adherence, we cannot assess the relationship between ART exposure and psychological distress. However, this study does have important strengths. The longitudinal design and time-varying assessments of disclosure provide a demonstration of the dynamic nature of psychological distress in relation to disclosure practices during the first year in HIV care.

In conclusion, this study adds to the growing body of literature underscoring the prevalence of psychological distress among PWH in SSA and its association with poor clinical outcomes. These findings demonstrate the urgency of integrated mental health screening and treatment services to support those in need, to improve both mental health and HIV care outcomes in the most heavily burdened regions of the world. To guide these interventions, future studies should also investigate and contextualize how factors like ART adherence and time on ART impact mental health, and optimal methods for diagnosing distress and suicidality in the face of dual stigma. In our cohort, older women who have delayed disclosure were found to have an extraordinarily high prevalence of psychological distress and are an important target for intervention. The WHO has recommended taskshifted mental health services in LMIC with limited infrastructure [61]. Problem solving therapy has been evaluated successfully for this purpose and is able to address critical psychosocial drivers of distress, such as social support and disclosure, and have shown success among other populations in this setting [62, 63]. Incorporating such models into HIV care should be a critical objective for HIV treatment programs in Nigeria and other LMIC.

Supplementary Information The online version contains supplementary material available at https://doi.org/10.1007/s12529-022-10068-8.
Funding The data in this manuscript have been supported by the National Institute of Allergy and Infectious Diseases (K23-AI106406) and the National Institute of Mental Health (R25-MH080665/MH/ NIMH NIH HHS/United States).

\section{Declarations}

Ethics Approval IRB approval was obtained from Partners HealthCare (Protocol No. P002460 Boston, MA, USA), the Nigerian Institute for Medical Research (Protocol No. 14/28 Lagos, Nigeria), and Vanderbilt University Medical Center (Protocol No. 161779 Nashville, TN, USA).

Informed Consent Informed consent was obtained from all individual participants included in the study.

Welfare of Animals (as Appropriate) N/A

Conflict of Interest The authors declare no competing interests.

\section{References}

1. The World Bank. Nigeria. [cited 11 Aug 2021]. Available: https:// data.worldbank.org/country/nigeria

2. NAIIS. National summary sheet. 2019. Available: https://www. naiis.ng/resource/factsheet/NAIIS\%20National\%20Summary\% 20Sheet.pdf

3. UNAIDS. Nigeria 2019. [cited 7 Apr 2020]. Available: https:// Www.unaids.org/en/regionscountries/countries/nigeria

4. UNAIDS. New survey results indicate that Nigeria has an HIV prevalence of $1.4 \%$. [cited $19 \mathrm{Jul}$ 2021]. Available: https://www.unaids. org/en/resources/presscentre/pressreleaseandstatementarchive/2019/ march/20190314_nigeria

5. INSIGHT START Study Group, Lundgren JD, Babiker AG, Gordin F, Emery S, Grund B, et al. Initiation of antiretroviral therapy in early asymptomatic HIV infection. N Engl J Med. 2015;373: 795-807. https://doi.org/10.1056/NEJMoa1506816

6. Rodger AJ, Cambiano V, Bruun T, Vernazza P, Collins S, van Lunzen J, et al. Sexual activity without condoms and risk of HIV transmission in serodifferent couples when the HIV-positive partner is using suppressive antiretroviral therapy. JAMA. 2016;316:171-81. https:// doi.org/10.1001/jama.2016.5148.

7. Bavinton BR, Pinto AN, Phanuphak N, Grinsztejn B, Prestage GP, Zablotska-Manos IB, et al. Viral suppression and HIV transmission in serodiscordant male couples: an international, prospective, observational, cohort study. Lancet HIV. 2018;5:e438-47. https:// doi.org/10.1016/S2352-3018(18)30132-2.

8. Parcesepe AM, Tymejczyk O, Remien R, Gadisa T, Kulkarni SG, Hoffman S, et al. Psychological distress, health and treatmentrelated factors among individuals initiating ART in Oromia. Ethiopia AIDS Care. 2018;30:338-42. https://doi.org/10.1080/ 09540121.2017.1363367.

9. Tlhajoane M, Eaton JW, Takaruza A, Rhead R, Maswera R, Schur $\mathrm{N}$, et al. Prevalence and associations of psychological distress, HIV infection and HIV care service utilization in East Zimbabwe. AIDS Behav. 2018;22:1485-95. https://doi.org/10.1007/ s10461-017-1705-x.

10. Parcesepe A, Tymejczyk O, Remien R, Gadisa T, Kulkarni SG, Hoffman S, et al. HIV-related stigma, social support, and psychological distress among individuals initiating ART in Ethiopia. AIDS Behav. 2018;22:3815-25. https://doi.org/10.1007/ s10461-018-2059-8. 
11. Abiodun O, Lawal I, Omokanye C. PLHIV are more likely to have mental distress: evidence from a comparison of a cross-section of HIV and diabetes patients at tertiary hospitals in Nigeria. AIDS Care. 2018;30:1050-7. https://doi.org/10.1080/09540121.2018. 1441973.

12. Egbe CO, Dakum PS, Ekong E, Kohrt BA, Minto JG, Ticao CJ. Depression, suicidality, and alcohol use disorder among people living with HIV/AIDS in Nigeria. BMC Public Health. 2017; 17:542. https://doi.org/10.1186/s12889-017-4467-5.

13. Lofgren SM, Bond DJ, Nakasujja N, Boulware DR. Burden of depression in outpatient HIV-infected adults in sub-Saharan Africa; systematic review and meta-analysis. AIDS Behav. 2020;24:1752-64. https://doi.org/10.1007/s10461-019-02706-2.

14. Katz IT, Ryu AE, Onuegbu AG, Psaros C, Weiser SD, Bangsberg DR, et al. Impact of HIV-related stigma on treatment adherence: systematic review and meta-synthesis. J Int AIDS Soc. 2013;16:18640. https://doi.org/10.7448/IAS.16.3.18640.

15. Evangeli M, Wroe AL. HIV disclosure anxiety: a systematic review and theoretical synthesis. AIDS Behav. 2017;21:1-11. https://doi.org/10.1007/s10461-016-1453-3.

16. Simbayi LC, Kalichman S, Strebel A, Cloete A, Henda N, Mqeketo A. Internalized stigma, discrimination, and depression among men and women living with HIV/AIDS in Cape Town. South Africa Soc Sci Med. 2007;64:1823-31. https://doi.org/10. 1016/j.socscimed.2007.01.006.

17. Chan BT, Tsai AC, Siedner MJ. HIV treatment scale-up and HIVrelated stigma in sub-Saharan Africa: a longitudinal cross-country analysis. Am J Public Health. 2015;105:1581-7. https://doi.org/ 10.2105/AJPH.2015.302716.

18. Gonzalez JS, Batchelder AW, Psaros C, Safren SA. Depression and HIV/AIDS treatment nonadherence: a review and meta-analysis. J Acquir Immune Defic Syndr. 2011;58. https://doi.org/10.1097/ QAI.0b013e31822d490a

19. Whetten K, Shirey K, Pence BW, Yao J, Thielman N, Whetten R, et al. Trauma history and depression predict incomplete adherence to antiretroviral therapies in a low income country. PLoS ONE. 2013;8: e74771. https://doi.org/10.1371/journal.pone.0074771.

20. Nakimuli-Mpungu E, Mojtabai R, Alexandre PK, Musisi S, Katabira E, Nachega JB, et al. Lifetime depressive disorders and adherence to anti-retroviral therapy in HIV-infected Ugandan adults: a casecontrol study. J Affect Disord. 2013;145:221-6. https://doi.org/10. 1016/j.jad.2012.08.002.

21. Sweetland AC, Norcini Pala A, Mootz J, Kao JC-W, Carlson C, Oquendo MA, et al. Food insecurity, mental distress and suicidal ideation in rural Africa: evidence from Nigeria, Uganda and Ghana. Int J Soc Psychiatry. 2019;65: 20-27. https://doi.org/10. $1177 / 0020764018814274$

22. Adewuya AO, Afolabi MO, Ola BA, Ogundele OA, Ajibare AO, Oladipo BF, et al. The effect of psychological distress on medication adherence in persons with HIV infection in Nigeria. Psychosomatics. 2010;51:68-73. https://doi.org/10.1176/appi.psy.51.1. 68.

23. Mutumba M, Musiime V, Lepkwoski JM, Harper GW, Snow RC, Resnicow K, et al. Examining the relationship between psychological distress and adherence to anti-retroviral therapy among Ugandan adolescents living with HIV. AIDS Care. 2016;28:80715. https://doi.org/10.1080/09540121.2015.1131966.

24. Beusenberg M, Orley JH, WHO. A user's guide to the self reporting questionnaire (SRQ). 1994 [cited 19 Jul 2021]. Available: https://apps.who.int/iris/handle/10665/61113

25. Netsereab TB, Kifle MM, Tesfagiorgis RB, Habteab SG, Weldeabzgi YK, Tesfamariam OZ. Validation of the WHO self-reporting questionnaire-20 (SRQ-20) item in primary health care settings in Eritrea. Int J Ment Health Syst. 2018;12:61. https://doi.org/10.1186/ s13033-018-0242-y.
26. van der Westhuizen C, Wyatt G, Williams JK, Stein DJ, Sorsdahl $\mathrm{K}$. Validation of the self reporting questionnaire 20-item (SRQ20) for use in a low- and middle-income country emergency centre setting. Int J Ment Health Addict. 2016;14:37-48. https://doi.org/ 10.1007/s11469-015-9566-x.

27. Nakimuli-Mpungu E, Mojtabai R, Alexandre PK, Katabira E, Musisi S, Nachega JB, et al. Cross-cultural adaptation and validation of the self-reporting questionnaire among HIV+ individuals in a rural ART program in southern Uganda. HIV AIDS (Auckl). 2012;4:51-60. https://doi.org/10.2147/HIV.S29818.

28. Ahonkhai AA, Adeola J, Banigbe B, Onwuatuelo I, Adegoke AB, Bassett IV, et al. Impact of unplanned care interruption on CD4 response early after ART initiation in a Nigerian cohort. J Int Assoc Provid AIDS Care. 2017;16:98-104. https://doi.org/10. 1177/2325957416672010.

29. Ahonkhai AA, Regan S, Idigbe I, Adeniyi O, Aliyu MH, Okonkwo $\mathrm{P}$, et al. The impact of user fees on uptake of HIV services and adherence to HIV treatment: findings from a large HIV program in Nigeria. PLoS ONE. 2020;15: e0238720. https://doi.org/10. 1371/journal.pone.0238720.

30. Ahonkhai AA, Banigbe B, Adeola J, Onwuatuelo I, Bassett IV, Losina $\mathrm{E}$, et al. High rates of unplanned interruptions from HIV care early after antiretroviral therapy initiation in Nigeria. BMC Infect Dis. 2015;15:397. https://doi.org/10.1186/s12879-015-1137-z.

31. Ahonkhai AA, Noubary F, Munro A, Stark R, Wilke M, Freedberg KA, et al. Not all are lost: interrupted laboratory monitoring, early death, and loss to follow-up (LTFU) in a large South African treatment program. PLoS ONE. 2012;7: e32993. https://doi.org/10.1371/ journal.pone.0032993.

32. Ahonkhai AA, Banigbe B, Adeola J, Adegoke AB, Regan S, Bassett IV, et al. Age matters: increased risk of inconsistent HIV care and viremia among adolescents and young adults on antiretroviral therapy in Nigeria. J Adolesc Health. 2016;59:298-304. https://doi.org/10. 1016/j.jadohealth.2016.05.002.

33. WHO. Mental health atlas 2017. [cited 19 Jul 2021]. Available: https://www.who.int/publications-detail-redirect/9789241514019

34. WHO, Ministry of Health Nigeria. WHO-AIMS report on mental health system in Nigeria. 2006. Available: https://www.who.int/ mental_health/evidence/nigeria_who_aims_report.pdf

35. Tao J, Qian H-Z, Kipp AM, Ruan Y, Shepherd BE, Amico KR, et al. Effects of depression and anxiety on antiretroviral therapy adherence among newly diagnosed HIV-infected Chinese men who have sex with men. AIDS. 2017;31:401-6. https://doi.org/ 10.1097/QAD.0000000000001287.

36. Ahmed S, Autrey J, Katz IT, Fox MP, Rosen S, Onoya D, et al. Why do people living with HIV not initiate treatment? A systematic review of qualitative evidence from low- and middle-income countries. Soc Sci Med. 2018;213:72-84. https://doi.org/10. 1016/j.socscimed.2018.05.048.

37. Xie J, Wang Z, Li Q, He Q, Xu G, Li Y, et al. Associations between antiretroviral therapy-related experiences and mental health status among people living with HIV in China: a prospective observational cohort study. Res Square 2020;10.21203

38. Ogundipe OA, Olagunju AT, Adeyemi JD. Suicidal ideation among attendees of a West African HIV clinic. Arch Suicide Res. 2015;19:103-16. https://doi.org/10.1080/13811118.2014.915776.

39. Oladeji BD, Taiwo B, Mosuro O, Fayemiwo SA, Abiona T, Fought AJ, et al. Suicidal behavior and associations with quality of life among HIV-infected patients in Ibadan, Nigeria. J Int Assoc Provid AIDS Care. 2017;16:376-82. https://doi.org/10.1177/ 2325957415617829.

40. Gureje O, Lasebikan VO, Kola L, Makanjuola VA. Lifetime and 12-month prevalence of mental disorders in the Nigerian Survey of Mental Health and Well-Being. Br J Psychiatry. 2006; 188:46571. https://doi.org/10.1192/bjp.188.5.465. 
41. Martinez P, Tsai AC, Muzoora C, Kembabazi A, Weiser SD, Huang Y, et al. Reversal of the Kynurenine pathway of tryptophan catabolism may improve depression in ART-treated HIV-infected Ugandans. J Acquir Immune Defic Syndr. 2014;65:456-62. https://doi.org/10.1097/QAI.0000000000000062.

42. Zangerle R, Widner B, Quirchmair G, Neurauter G, Sarcletti M, Fuchs D. Effective antiretroviral therapy reduces degradation of tryptophan in patients with HIV-1 infection. Clin Immunol. 2002;104:242-7. https://doi.org/10.1006/clim.2002.5231.

43. Uthman OA, Magidson JF, Safren SA, Nachega JB. Depression and adherence to antiretroviral therapy in low-, middle- and high-income countries: a systematic review and meta-analysis. Curr HIV/AIDS Rep. 2014;11:291-307. https://doi.org/10.1007/ s11904-014-0220-1.

44. Adejumo O, Oladeji B, Akpa O, Malee K, Baiyewu O, Ogunniyi A, et al. Psychiatric disorders and adherence to antiretroviral therapy among a population of HIV-infected adults in Nigeria. Int J STD AIDS. 2016;27:938-49. https://doi.org/10.1177/0956462415600582.

45. Ironson G, O'Cleirigh C, Fletcher MA, Laurenceau JP, Balbin E, Klimas N, et al. Psychosocial factors predict CD4 and viral load change in men and women with human immunodeficiency virus in the era of highly active antiretroviral treatment. Psychosom Med. 2005;67:1013-21. https://doi.org/10.1097/01.psy.0000188569. 58998.c8.

46. Greeson JM, Hurwitz BE, Llabre MM, Schneiderman N, Penedo FJ, Klimas NG. Psychological distress, killer lymphocytes and disease severity in HIV/AIDS. Brain Behav Immun. 2008;22:90111. https://doi.org/10.1016/j.bbi.2008.01.001.

47. Evans DL, Ten Have TR, Douglas SD, Gettes DR, Morrison M, Chiappini MS, et al. Association of depression with viral load, CD8 T lymphocytes, and natural killer cells in women with HIV infection. Am J Psychiatry. 2002;159:1752-9. https://doi.org/10. 1176/appi.ajp.159.10.1752.

48. Yousuf A, Mohd Arifin SR, Musa R, Md. Isa ML. Depression and HIV disease progression: a mini-review. Clin Pract Epidemiol Ment Health. 2019;15: 153-159. https://doi.org/10.2174/ 1745017901915010153

49. Ironson G, O'Cleirigh C, Kumar M, Kaplan L, Balbin E, Kelsch $\mathrm{CB}$, et al. Psychosocial and neurohormonal predictors of HIV disease progression (CD4 cells and viral load): a 4 year prospective study. AIDS Behav. 2015;19:1388-97. https://doi.org/10.1007/ s10461-014-0877-x.

50. Kola L. Global mental health and COVID-19. Lancet Psychiatry. 2020;7:655-7. https://doi.org/10.1016/S2215-0366(20)30235-2.

51. Krumme AA, Kaigamba F, Binagwaho A, Murray MB, Rich ML, Franke MF. Depression, adherence and attrition from care in HIV-infected adults receiving antiretroviral therapy. J Epidemiol Community Health. 2015;69:284-9. https://doi.org/10.1136/ jech-2014-204494.

52. Grieb SM, Kerrigan D, Tepper V, Ellen J, Sibinga E. The clinic environment as a form of social support for adolescents and young adults living with HIV. AIDS Patient Care STDS. 2018;32:20813. https://doi.org/10.1089/apc.2018.0012.
53. Adeoye-Agboola DI, Evans H, Hewson D, Pappas Y. Factors influencing HIV disclosure among people living with HIV/AIDS in Nigeria: a systematic review using narrative synthesis and meta-analysis. Public Health. 2016;136:13-28. https://doi.org/ 10.1016/j.puhe.2016.02.021.

54. Maman S, van Rooyen H, Groves AK. HIV status disclosure to families for social support in South Africa (NIMH Project Accept/ HPTN 043). AIDS Care. 2014;26:226-32. https://doi.org/10. 1080/09540121.2013.819400.

55. Jiang M, Yang J, Song Y, Zheng J, Li X, Yang G, et al. Social support, stigma, and the mediating roles of depression on selfreported medication adherence of HAART recipients in China. AIDS Care. 2019;31:942-50. https://doi.org/10.1080/09540121. 2019.1587360.

56. Brown MJ, Serovich JM, Laschober TC, Kimberly JA, Lescano CM. Mediating effects of depressive symptoms on perceived social support and HIV disclosure: assessing moderation by sex. AIDS Behav. 2019;23:636-48. https://doi.org/10.1007/ s10461-018-2369-x.

57. Albert PR. Why is depression more prevalent in women? J Psychiatry Neurosci. 2015;40:219-21. https://doi.org/10.1503/jpn. 150205.

58. Gupta R, Dandu M, Packel L, Rutherford G, Leiter K, Phaladze N, et al. Depression and HIV in Botswana: a population-based study on gender-specific socioeconomic and behavioral correlates. PLoS ONE. 2010;5: e14252. https://doi.org/10.1371/journal.pone.0014252.

59. Vosvick M, Martin LA, Smith NG, Jenkins SR. Gender differences in HIV-related coping and depression. AIDS Behav. 2010;14:390-400. https://doi.org/10.1007/s10461-008-9490-1.

60. Swendeman D, Fehrenbacher AE, Roy S, Das R, Ray P, Sumstine $\mathrm{S}$, et al. Gender disparities in depression severity and coping among people living with HIV/AIDS in Kolkata. India PLoS One. 2018;13: e0207055. https://doi.org/10.1371/journal.pone.0207055.

61. Caulfield A, Vatansever D, Lambert G, Van Bortel T. WHO guidance on mental health training: a systematic review of the progress for non-specialist health workers. BMJ Open. 2019;9: e024059. https://doi.org/10.1136/bmjopen-2018-024059.

62. Oladeji BD, Kola L, Abiona T, Montgomery AA, Araya R, Gureje O. A pilot randomized controlled trial of a stepped care intervention package for depression in primary care in Nigeria. BMC Psychiatry. 2015;15:96. https://doi.org/10.1186/s12888-015-0483-0.

63. Gureje O, Oladeji BD, Montgomery AA, Bello T, Kola L, Ojagbemi A, et al. Effect of a stepped-care intervention delivered by lay health workers on major depressive disorder among primary care patients in Nigeria (STEPCARE): a cluster-randomised controlled trial. Lancet Glob Health. 2019;7:e951-60. https://doi.org/10.1016/S2214109X(19)30148-2.

Publisher's Note Springer Nature remains neutral with regard to jurisdictional claims in published maps and institutional affiliations. 